\title{
Impact of Northwest Atlantic SST Anomalies on the Circulation over the Ural Mountains during Early Winter
}

\author{
Shuanglin LI \\ NOAA-CIRES Climate Diagnostics Center, University of Colorado, Boulder, Colorado, U.S.A.
}

(Manuscript received 26 August 2003, in final form 5 March 2004)

\begin{abstract}
Both the observed background circulation and the northwest Atlantic sea surface temperature anomalies (SSTA) associated with the circulation anomaly over the Ural Mountains during early winter (October-December) are investigated, and it is shown that a positive height anomaly over the Urals is remotely linked to a positive SSTA by an upper wave-train-like anomaly chain across the North Atlantic and coastal Europe. To investigate whether and how the SSTA affects the circulation over the Urals, large-ensemble atmospheric general circulation model (GCM) experiments are conducted, and the results show that the SSTA forces a similar wave-train-like anomaly chain, resulting in a positive geopotential height anomaly over the Urals.

The mechanism that maintains the response is diagnosed by investigating the roles of anomalous diabatic heating, and transient vorticity forcing, via a linear baroclinic model (LBM). The results suggest that the two upstream anomalies in the chain are largely maintained by anomalous transient vorticity forcing, although it is modulated by anomalous diabatic heating. In contrast, the Ural response is largely maintained by anomalous diabatic heating. To mimic the initial mechanism of the response, an idealized heating representing the initial SSTA-induced heating is prescribed. The LBM response to the idealized heating is obtained, and then transient feedback to the heating-induced anomalous flow is simulated, via a linear storm track model (STM). The LBM responses to the anomalous transient vorticity forcing resulting from the idealized heating resembles the GCM simulation upstream, but is not significant over the Urals. This suggests further that the Ural response is triggered, and maintained, by anomalous diabatic heating.
\end{abstract}

\section{Introduction}

The region around the Ural Mountains is one of three regions with the maximum occurrence of persistent circulation anomalies in boreal winter (Dole and Gordon 1983). The circulation anomalies over the sector have important affects upon East Asian weather and climate (e.g., Ye et al. 1962). A positive/negative anomaly of seasonal $500-\mathrm{hPa}$ height represents enhanced/weakened blocking activity over the

Corresponding author: Shuanglin Li, NOAACIRES CDC, R/CDC1, 325 Broadway, Boulder, CO 80305-3328, USA.

E-mail: shuanglin.li@noaa.gov

(C) 2004, Meteorological Society of Japan sector. Synoptically, the twin-blocking pattern, one blocking over the Urals and another over the Sea of Okhotsk, with a low around Lake Baikal between the two blockings, is one of the primary circulation patterns that produce southward outbreaks of cold air, which are most severe over East Asia in early winter. Climatologically, a strong positive height anomaly over the Urals in early winter is related to a colder surface temperature than normal in East Asia. Thus, for the early wintertime seasonal prediction of East Asia, the circulation over the Urals is one of the critical factors.

Due to the dominant role of atmospheric internal variability at mid-latitudes, seasonal prediction of the circulation over this sector be- 
comes a challenging and difficult project. The critical factor lies in finding the lower boundary anomaly (i.e. ocean and land), which modulates the atmospheric variability on seasonal and longer timescales. Previous studies suggest that the circulation anomaly over the Urals is related to a wave-train-like height anomaly chain upstream, originating from the North Atlantic in observations, both in summer ( $\mathrm{Li}$ and Ji 2001), and in early winter (Palmer and Sun 1985, in brief PS85 hereafter). Therefore, a natural question is whether there exists an association between the height anomaly chain, and North Atlantic sea surface temperature anomalies (SSTA), or, further, whether the North Atlantic SSTA can impact the chain, thus influencing the Urals. Finally, if the influence exists, through what mechanism is the influence initiated and maintained? In the present study, we will investigate these questions.

The observational composite in this paper suggests that a northwest Atlantic positive SSTA is linked to the height anomaly chain in early winter (October-December). Such an SSTA is located in one of the most dynamically, and thermodynamically active regions of the extratropical atmosphere (Namias 1973), so its possible influence on the overlying atmosphere has been the focus of numerous investigations (e.g., Namias 1964 and 1973; PS85; Peng et al. 1995; Kushnir and Held 1996). However, diverse and inconsistent results are obtained by different authors, and, correspondingly, whether the SSTA affects remotely on the Urals or not, is also inconsistent. PS85 used a version of the United Kingdom (U.K.) Meteorological Office's general circulation model (GCM), to conduct 4 pairs of 50-day wintertime integrations with initial fields from November analyses of four consecutive years. Each pair of runs was performed with two different sea surface boundary conditions, with either warm or cold SSTA of about $3 \mathrm{~K}$ amplitude, prescribed in the northwest Atlantic. Their simulations produced a positive height anomaly over the Atlantic and another negative anomaly over the Mediterranean to Europe. Both anomalies are in agreement with the observational composite. However, they obtained no significant response over the Urals, inconsistent with their synchronous observational composite (cf. their Fig. 2 with Figs. 10-11). Peng et al. (1995) conducted a similar study by using the global spectral model of the Division de la Recherche en Prevision Numerique (RPN), of the Atmospheric Environment Service of Canada. They studied the atmospheric response to a similar SSTA in early winter (November), and in midwinter (January) separately, by performing ensemble runs with 6 members for November and 4 members for January. Their results demonstrated that the response is not the same in the two different seasons, and thus is seasonally dependent, or dependent on the background circulation. They obtained a strong positive barotropic height response over the Atlantic, and a weak positive response over the Urals in November (see their Fig. 2). The former response is in agreement with PS85, but not the latter response. In January, the response over the North Atlantic is negative, despite being barotropic, and is totally different from the November response. The response over the Urals is not significant. Kushnir and Held (1996) studied the atmospheric response to localized extratropical SSTA, using long integrations with a low-resolution (R15) GCM, with realistic and idealized SST. Their results demonstrated that the geopotential height displays a baroclinic response with a shallow anomalous low somewhat downstream from the warm North Atlantic SSTA. Over the Urals, there is a positive, but slightly shifted to the north, height response in October (see their Fig. 12). They argued that the significant difference of their results from other simulations, baroclinic versus barotropic, could be attributed to the weak representation of transient variability in their coarse resolution GCM. In summary, the atmospheric response to northwest Atlantic SSTA, both over the North Atlantic locally, and the Urals remotely, is inconsistent.

In recent years, significant progress has been made in reconciling the inconsistency and diversity of simulated atmospheric responses to midlatitude SSTA in different studies (Kushnir et al. 2002; Peng and Robinson 2001). These studies suggest that a midlatitude SSTA does not force a new mode of variability in the atmosphere. Instead, it only shifts the distributions and changes the variances of existing internal modes. This is caused by the interaction between the SST-forced direct response (thermal, and thus baroclinic), and the storm track 
(e.g., Peng and Whitaker 1999; Ting and Peng 1995). A stable atmospheric response, resulting from this interaction, is primarily maintained by anomalous transient vorticity fluxes. This is the same case as the maintenance of the internal low-frequency variability. The primary contributor to the internal low-frequency circulation anomaly is the forcing from anomalous distributions of transient momentum fluxes (Branstator 1995). Thus, the SST-forced response and internal low-frequency variability share the same dynamics, in that both are primarily maintained by transient forcing. This explains why the SST-forced response projects strongly on the low-frequency pattern (Peng and Robinson 2001; Hall et al. 2001). Therefore, whether one GCM can simulate the atmospheric response to the mid-latitude SSTA depends on whether the model reproduces intrinsic low frequency and storm track variability in the same way as in the observed atmosphere. Even now, no model reproduces intrinsic variability in observational atmosphere perfectly. Model deficiencies, therefore, distort the modeled response. By comparing the intrinsic variability in the model and in observations, we can expect to explain, to some extent, the atmospheric response to mid-latitude SSTA.

In view of the possible remote impact of the northwest Atlantic SSTA on the Urals, and the inconsistent results obtained in previous studies, as well as the above progress in understanding the atmospheric response to midlatitude SSTA, we conduct large ensemble experiments with 100 members to investigate the SSTA influence in the National Centers for Environmental Prediction (NCEP)'s seasonal prediction GCM. Later sections will suggest that this model simulates observational variability over the North Atlantic reasonably, despite significant deficiencies over the North Pacific. Such a large ensemble may be necessary to get the atmospheric response to the mid-latitude SSTA, considering the low ratio of the SSTforced signal to the strong internal variability (Peng et al. 2003).

This paper is organized as follows: in section 2 , the observed background circulation and North Atlantic SSTA associated with circulation anomalies over the Urals are investigated by composite analyses and regression; section 3 introduces the models and the experiments.
The NCEP GCM and two idealized linear models, a linear baroclinic model and a storm track model, are described. The design of two sets of experiments is introduced in brief; in section 4, GCM-simulated intrinsic variability, and the simulated response to the SSTA are displayed. The roles of anomalous transient forcing and diabatic heating in the maintenance of responses are diagnosed; in section 5 , the initial mechanism of the response is diagnosed by prescribing an idealized heating and by investigating the direct atmospheric response to the heating and transient feedback to the heatinginduced response. A summary and discussion are given in the last section.

\section{Observation analyses}

The National Centers for Environment Prediction-National Center for Atmospheric Research (NCEP-NCAR) reanalysis monthly mean height, $Z$, and horizontal wind, $u$ and $v$, from October to December in 1948-2000 (Kalnay et al. 1996), and the Global Ice and Sea Surface Temperature dataset (GISST) (Rayner et al. 1996) from October to December in 19461998, are used in the observational analyses.

First, we address the background circulation associated with the Ural anomaly. For this purpose, the composite for the months when normalized monthly $500-\mathrm{hPa}$ geopotential height over the Urals has a large positive/negative anomaly is calculated. Here, monthly height anomalies are normalized by the monthly standard deviation for individual months from October to December. Monthly anomalies are calculated as the monthly height difference from the climatological monthly average in the 53 years, 1948-2000. When the normalized height anomaly at the key point $\left(60^{\circ} \mathrm{E}, 60^{\circ} \mathrm{N}\right)$ representing the Urals in one month is greater than 0.8 (less than -0.8), a positive (negative) anomaly month case is defined. According to this criterion, a total of $34 / 37$ positive/negative anomaly months is defined for October to December in 1948-2000. Monthly anomalies for the positive/negative months are grouped together to form the positive/negative anomaly composite, individually.

Figure 1 shows an equivalent-barotropic wave-train-like height anomaly chain, with a positive anomaly over the central North Atlantic, and a negative anomaly over coastal $\mathrm{Eu}-$ 
(a)

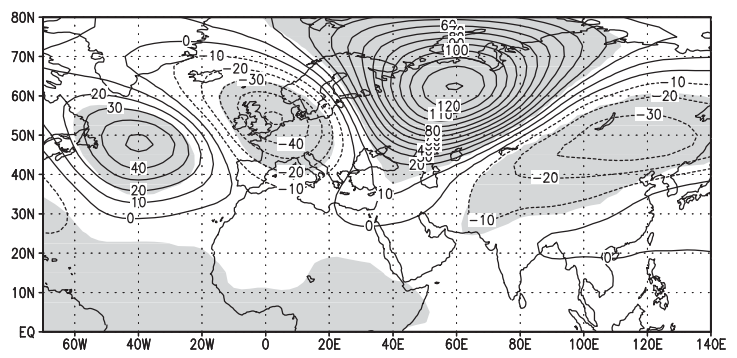

(c)

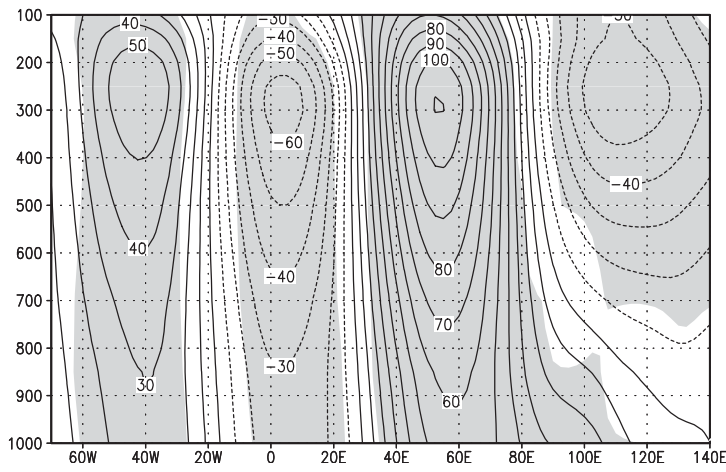

(b)

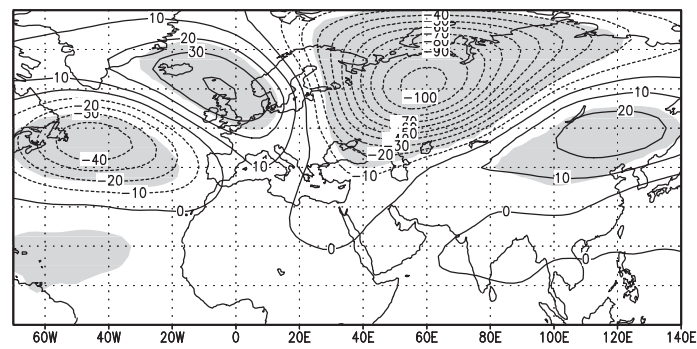

(d)

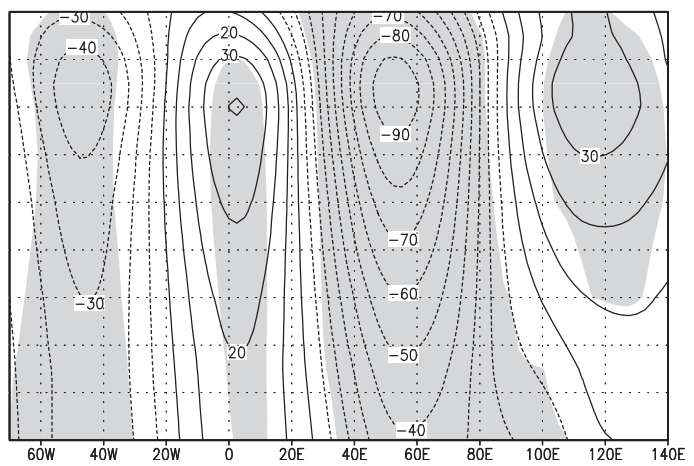

Fig. 1. Composite of 500-hPa geopotential height anomaly and the cross-section along $52.5^{\circ} \mathrm{N}$. (a)(c) for the 34 Ural positive anomaly months and (b)(d) for the 37 Ural negative anomaly months from October to December in the 1948-2000 NCEP-NCAR reanalysis. Unit: $\mathrm{m}$. Shaded area is at the 95\% significance level.

rope when the Ural anomaly is positive. They are reversed when the Ural anomaly is negative. This suggests that the anomaly over the Urals can be linked to the North Atlantic by the anomaly chain across the Atlantic and Europe.

Figure 2 displays the difference of the composite SSTA when the Ural anomaly is positive and when it is negative. A significant positive SSTA, with a maximum magnitude of $0.7 \mathrm{~K}$, is found in the North Atlantic, slightly upstream relative to the positive North Atlantic height anomaly (Fig. 1a). When compared the composite SSTA for the positive Ural anomaly months to that for the negative months (not shown), the former shows the reversed pattern to the latter. The composite SSTA difference resembles the leading pattern of the SST variability in this season (Czaja and Frankignoul 2002; Drevillon et al. 2001). Whether such an SSTA is physically linked to the height anomaly chain is intriguing.

Figure 3 displays the regressions of observed $500-\mathrm{hPa}$ height and SST on the time series

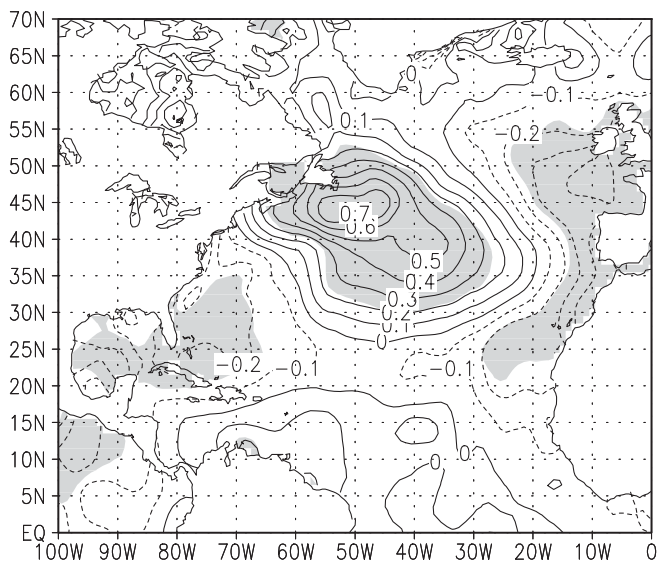

Fig. 2. Composite SSTA difference between the 34 Ural positive anomaly months and the 37 Ural negative anomaly months. Unit: K. Shaded area is at the $95 \%$ significance level. 

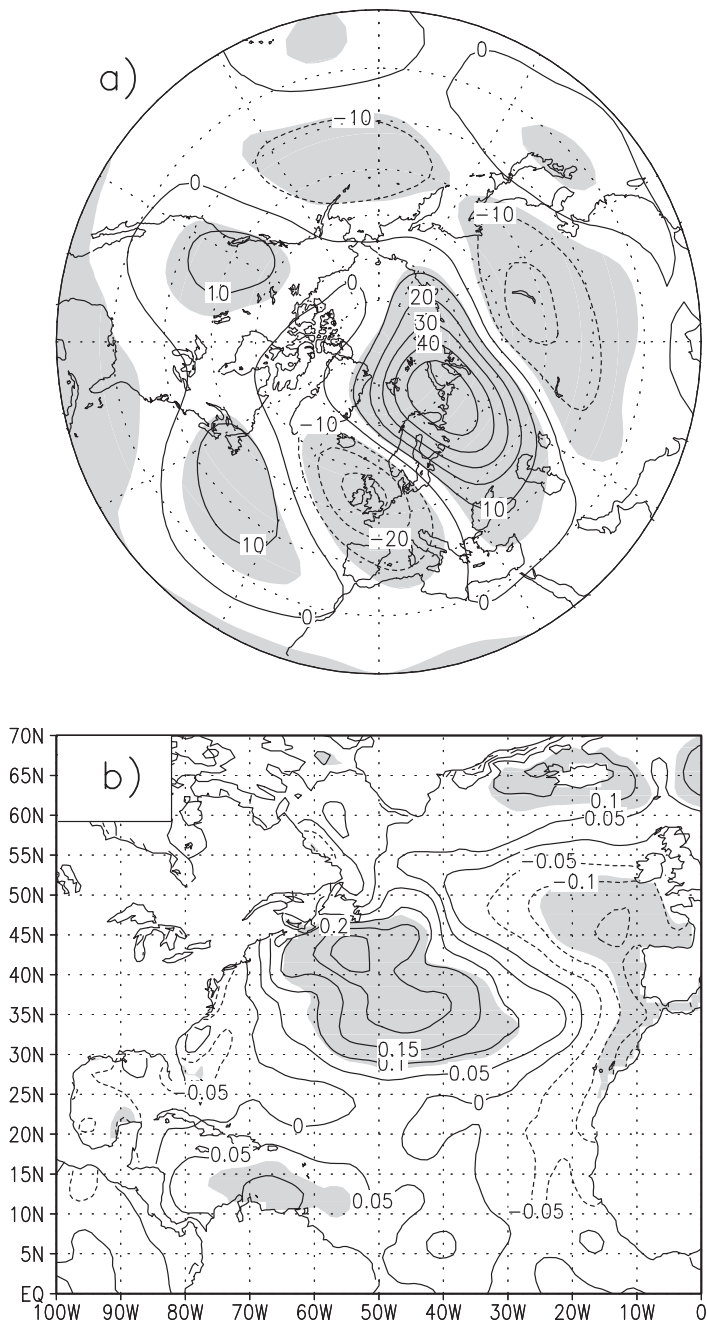

Fig. 3. Regression of October-December mean observed 500-hPa height (a) and observed SST (b) on the time coefficient of the leading EOF of OctoberDecember mean 500-hPa height. The leading EOF explains $27.2 \%$ of the total variance. The EOF analysis is conducted by solving the covariance matrix of October-December mean height anomalies interpolated over equal-area grids, and the analysis domain is the North Atlantic (90W-0-90E, 20$87.5 \mathrm{~N})$. Unit: $\mathrm{m}$ in (a) and $\mathrm{K}$ in (b). Shading represents anomalies that are correlated with the time coefficient of the leading EOF at the 95\% significance level. of the leading empirical orthogonal function (EOF) of October-December mean $500-\mathrm{hPa}$ height over the North Atlantic sector. From Fig. 3a, the height regression is dominated by a wave-train-like chain, with a robustly positive anomaly over the Urals. Evidently, the anomaly chain resembles the composite height anomaly (Fig. 1). The observed SST regression plot (Fig. 3b) displays a positive SSTA over the North Atlantic, also similar to the SST composite difference in Fig. 2. This suggests that such an SSTA is linearly linked to the height anomaly chain associated with the Ural circulation anomaly. Whether the SST anomaly can act as forcing to the height anomaly chain, deserves investigation. The issue is explored using GCM simulations.

\section{Models and experiments}

\subsection{GCM}

The GCM used here is a version of NCEP's operational seasonal forecast model with T42 horizontal resolution, and 28 vertical sigma levels. A similar GCM, but with T62 resolution, is used in the NCEP-NCAR reanalysis (Kalnay et al. 1996). Two types of ensemble runs, with an ensemble size of 100 , are conducted for 8 months from September to April, one with the climatological SST, and the other with the Atlantic SSTA (Fig. 4) added to the climatological SST. The former are referred to as control runs and the latter as SSTA runs. Because of the small signal-noise ratio in the extratropics, such large ensembles are necessary to get a

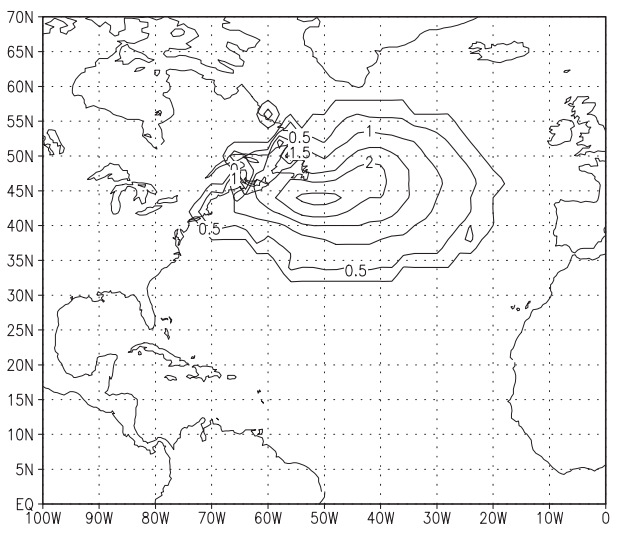

Fig. 4. SSTA used in the GCM runs. Unit: $\mathrm{K}$. 
steady and significant response (Peng et al. 2003). The 100 initial fields of the runs are from the NCEP-NCAR reanalysis of 12UTC, September 1-5, 1980-1999. The SSTA prescribed is from PS85, but has a smaller maximum value. Such a central magnitude is about twice as great as monthly SST standard deviation, and is within the range of observed SSTA in early winter. Evidently, the SSTA resembles both the observational composite (Fig. 2), and the SST regression pattern on the time series of the leading EOF (Fig. 3b). In the sections below, the response is calculated as the ensemble mean difference between the SSTA runs and the control runs.

\subsection{Linear baroclinic model}

In order to diagnose the roles of different forcing terms in the maintenance of the atmospheric response to the SSTA, and the direct atmospheric response to the SST-induced heating anomaly, a linear baroclinic model (LBM) is employed. The LBM is a time-dependent model based on the primitive equations including five basic equations describing the vorticity, divergence, temperature, mass, and hydrostatic balances. It is a global spectral model with horizontal resolution of T21 truncation, and 10 equally-spaced vertical pressure levels. No topography is prescribed at the lower boundary. The LBM is integrated forward in time, and the role of the individual forcing term is estimated by the LBM response when a steady response state is reached. The basic state for the LBM is derived from the seasonal mean for OctoberDecember. Two basic flows are obtained. One is the GCM's basic flow, which is derived from the 100 control runs, and the other is the observed basic flow, derived from the NCEP-NCAR reanalysis in 1948-2000. Both basic flows are used when studying the maintenance of the GCM response, and only the observational one is used when studying the atmospheric response to an idealized SST-induced heating. The main forcings in the LBM are diabatic heating and transient vorticity flux convergence. In order to obtain the stable response to the forcing, appropriate dissipation strength is needed. For the observed basic flow, Rayleigh friction and Newtonian damping are given the rate of $(1 \text { day })^{-1}$ at the lowest level, and

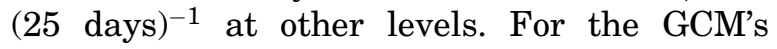

basic flow, a slightly stronger dissipation rate, (15 days $)^{-1}$, is given above the lowest level. A biharmonic diffusion with a coefficient of $2 \times 10^{16} \mathrm{~m}^{4} \mathrm{~s}^{-1}$ is applied in the vorticity, divergence, and thermodynamic equations for both the basic flows, and it damps the highest resolved wavenumber on a 4.5-day timescale. A thermal diffusion with a coefficient of $2 \times 10^{6} \mathrm{~m}^{2} \mathrm{~s}^{-1}$ is applied for both the basic flows to represent thermal effect by transient eddies. A quasi-steady state is generally achieved after about 60 days under these damping terms, so the average of the last 5 days of a $60-$ day integration is approximated as the steady solution. A detailed description of the model can be seen in Peng and Whitaker (1999).

\subsection{Linear storm track model}

Transient vorticity forcing plays a very important role in the maintenance of the timemean flow. At the same time, transient activity is modulated by time-mean flow (e.g., Branstator 1995). In order to determine the synoptic eddy statistics associated with a given mean flow, linear storm track models (STM) were developed by different researchers (Branstator 1995; Whitaker and Sardeshmukh 1998; Peng et al. 2003). In the present study, an STM is used to estimate transient feedback to the time-mean flow anomaly induced by heating. It is an updated version of the STM developed by Whitaker and Sardeshmukh (1998), with a horizontal resolution of T31 truncation and five equally-spaced vertical pressure levels. The scaling parameter, $\varepsilon$, in the STM (see EQ. 7a of Whitaker and Sardeshmukh 1998), which determines the magnitude of the stormtrack activity, is chosen so that the simulated 300$\mathrm{hPa}$ transient kinetic energy, for observed basic state, matches observations. Rayleigh friction and Newtonian damping are assigned timescales of 0.4 days at lowest level and 4 days above. The coefficient of biharmonic diffusion is set to $5 \times 10^{16} \mathrm{~m}^{4} \mathrm{~s}^{-1}$. Such a diffusion damps the highest resolved wavenumber (T31) on a 0.39-day timescale. The strong damping is necessary to make the simulated storm track close to that observed. To determine climatological transient statistics, the time-mean flow for the STM is the climatological seasonal mean for October to December, derived from the 19482000 NCEP-NCAR Reanalysis. When inves- 
tigating transient feedback to the heatinginduced anomalous flow, the time-mean flow is the climatological flow overlapped by the heating-induced anomalous flow. Thus, the difference of transient eddy statistics under the two flows reflects the transient feedback on the heating-induced anomalous flow associated with the SSTA.

\section{Modeled response and its maintenance}

\subsection{GCM's intrinsic variability}

As mentioned in the introduction, the model's atmospheric response to the midlatitude SSTA strongly depends on the model's intrinsic variability, low-frequency pattern and storm track. The model's deficiency in representing intrinsic variability, will distort the model's atmospheric response. Therefore, it is necessary to check the intrinsic variability of the model used here in order to better understand the model response.

Figure 5 displays the model's intrinsic variability, together with its comparison to the observations. From Figs. 5a and b, the distribution and amplitude of standard deviation (SDV hereafter) of $500-\mathrm{hPa}$ monthly geopotential heights in the model, are close to the observations over the North Atlantic, but those around the Urals are significantly smaller than the observations. In observations, there is a maximum in SDV with the value of $80 \mathrm{~m}$ over the Urals (Fig. 5a), while only about $45 \mathrm{~m}$ in the model. Because low-frequency variability contributes the greatest portion of the monthly variance, the result in Fig. 5b suggests the low-frequency variability around the Urals is deficient in the model. This point is confirmed by the leading $\mathrm{EOF}$ of $500-\mathrm{hPa}$ geopotential height. From Figs. 5c and d, the pattern of the leading EOF over the sector in the model resembles the observed one, in that both display a wave-train-like chain from the North Atlantic to the Urals. Comparing the amplitudes over the different local sectors composing the chain, the value over the Urals is twice as great as that over the Atlantic in the observations. This ratio can also be found in the leading EOF over a greater domain, the northern hemisphere (not shown). In strong contrast, the value over the Urals is 3.5 times smaller than that over the North Atlantic in the model. This suggests that the low frequency variability over the
Urals in the model is severely deficient relative to the observations.

Figures 5e-h compare the model's transient stream function variance, and stream function tendency due to transient vorticity flux convergence, with those in the observations. A "poor man's filter" is used to obtain the synoptic components with timescales less than 9 days for both the reanalysis dataset and the model output. A similar filter was used by PS85. Adopting such a filter is a compromised choice in view of the short time series of daily model's output in each individual GCM run. For example, the original daily variables for the filter are available only from September 5 to April 30 for the runs starting from September 5, even if the model's spin-up period is included. In view of a spin-up period needed for the GCM, the transient component on October 1 cannot be isolated via other temporal filters needing more data points. A test performed using the observed dataset shows no significant differences from a 61-point filter, which was used to isolate the transient component with the time scales of 3-10 days. From Figs. 5e-h, the model reproduces the observed storm track over the North Atlantic, but the model's Pacific storm track does not compare as well (not shown). Correspondingly, the leading EOF over the $\mathrm{Pa}$ cific domain is significantly different from the observational one over the domain. This also results in a great difference between the leading EOF of observational $500-\mathrm{hPa}$ height over the northern hemisphere domain, and that in the model.

In summary, the model captures the North Atlantic storm track and generally reproduces the wave-like low frequency variability pattern from the North Atlantic to the Urals, but it seriously underestimates the low-frequency variability over the Urals. It also fails to reproduce the observed intrinsic variability over the North Pacific.

\subsection{GCM simulated response}

Figure 6 displays the ensemble mean difference of $500-\mathrm{hPa}$ geopotential height and its vertical cross-section along $52.5^{\circ} \mathrm{N}$ between the SSTA runs and the control runs for October to December. One can see a significant barotropic wave-train-like height response across the North Atlantic and coastal Europe to the 
OBS

a)

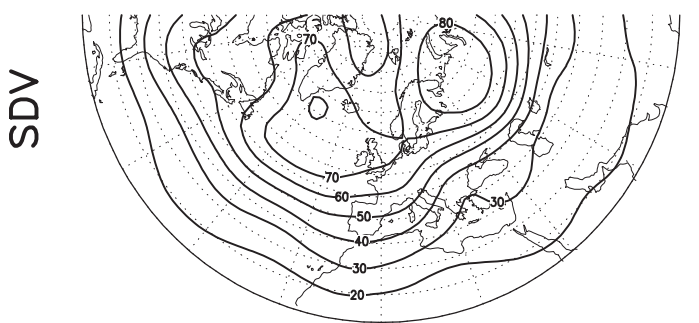

c)

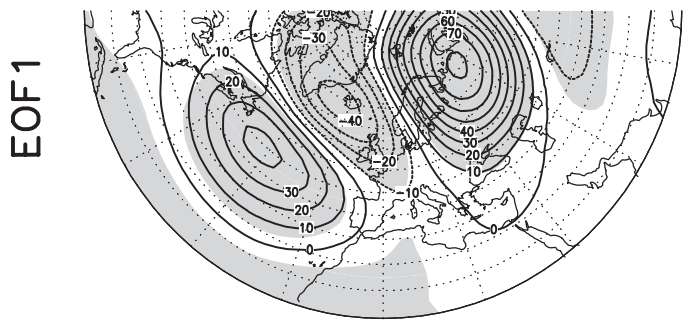

e)

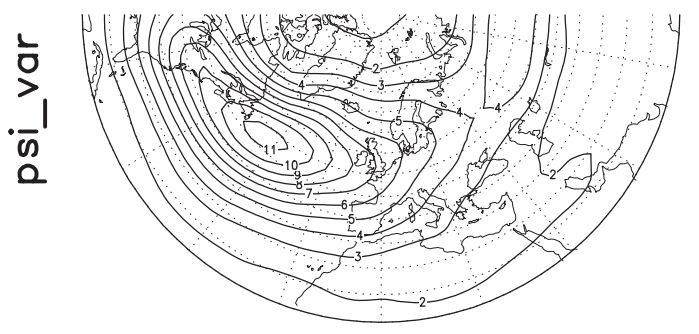

g)

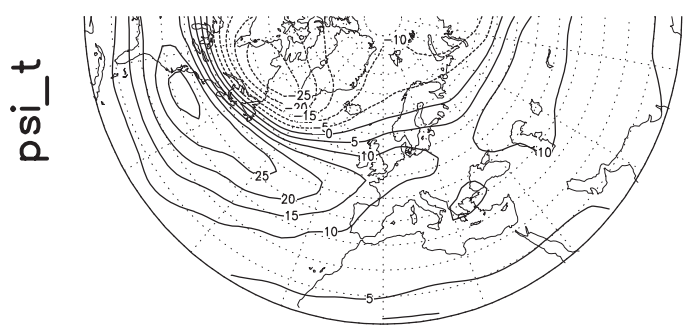

AGCM

b)

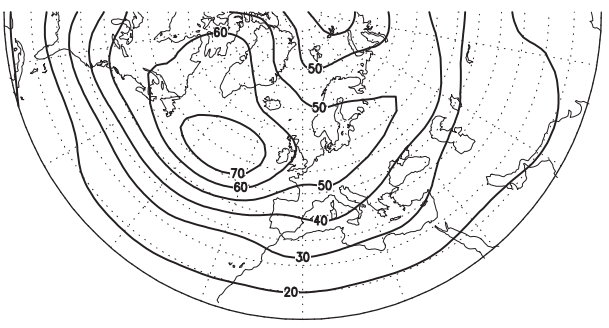

d)

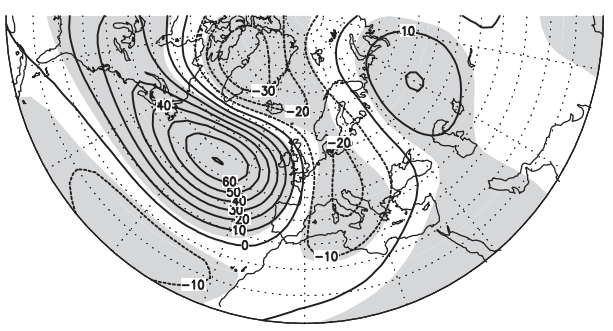

f)

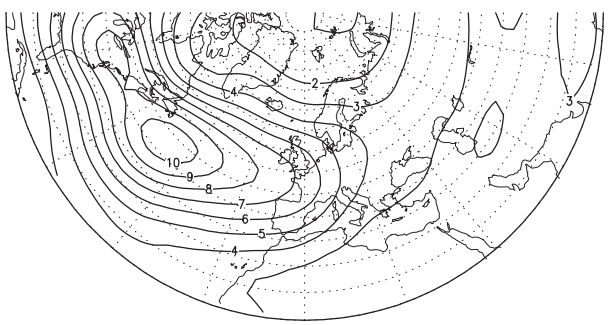

h)

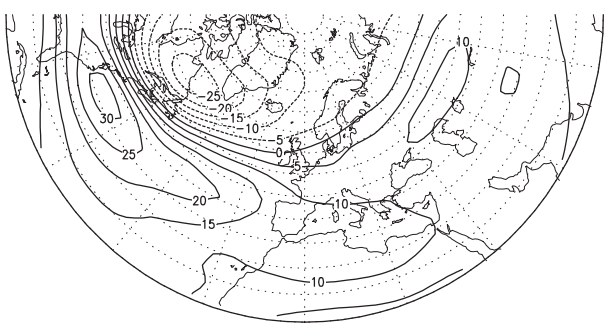

Fig. 5. NCEP GCM's intrinsic variability, low-frequency pattern and storm track, and its comparison with the observations from the 1948-2000 NCEP-NCAR reanalysis. Left panels are for the observations, and right panels are for the 100 GCM control runs. In (a) and (b) is the mean of the standard deviation (SDV) of 500-hPa monthly geopotential height from October to December. Unit: $\mathrm{m}$. In (c) and (d) is the leading EOF of 500-hPa monthly height for October to December. The EOF analysis domain is (90W-0-90E, 20-87.5N), and the analysis is conducted over equal-area grids. The variance explained by the leading EOF is $22 \%$ for the observations and $19 \%$ for the 100 GCM control runs. In (e) and (f) is the $250-\mathrm{hPa}$ transient stream function variance. Unit: $10^{13} \mathrm{~m}^{4} \mathrm{~s}^{-2}$. In (g) and $(\mathrm{h})$ is the $250-\mathrm{hPa}$ transient stream function tendency due to transient vorticity flux convergence. Unit: $\mathrm{m}^{2} \mathrm{~s}^{-2}$. See the text for the filters used to define transient eddies. Shading in (c) and (d), as in Fig. 3, represents height anomalies that are correlated with the time coefficient of the leading EOF at the $95 \%$ significance level. 
(a)

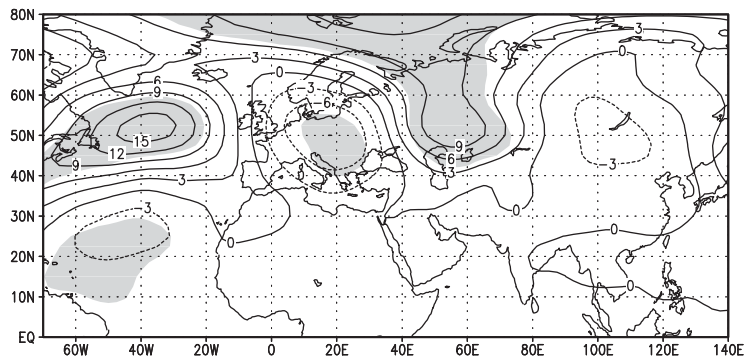

(b)

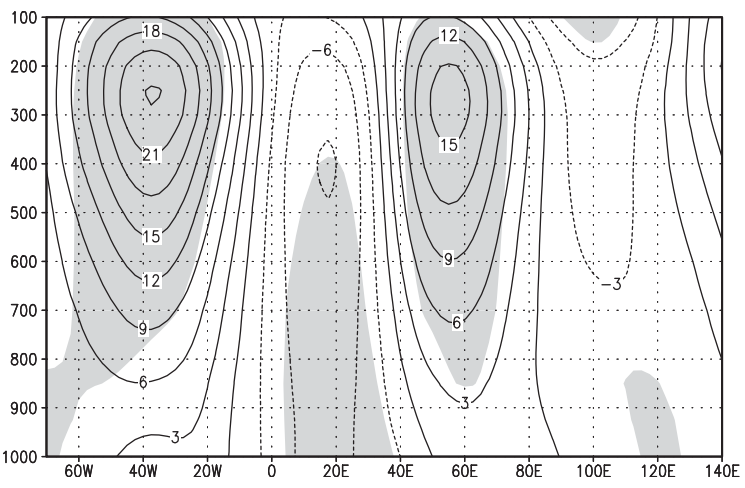

Fig. 6. October-December mean GCM geopotential height response at 500$\mathrm{hPa}$ (a), and the cross-section along $52.5^{\circ} \mathrm{N}$ (b). Unit: $\mathrm{m}$. Shaded area is at the $95 \%$ significance level.

Urals, with the maximum magnitude at 250$\mathrm{hPa}$. The response is similar to the observed composite background circulation associated with the Ural anomaly (Fig. 1). This demonstrates that the SSTA can induce a wave-trainlike height anomaly chain with a positive height response over the Urals. Such a response is also reflected in other variables, e.g., air temperature.

Comparing the present response with previous studies (e.g., PS85; Peng et al. 1995), the upstream anomalies are qualitatively in agreement with PS85's simulated December response and Peng et al.'s November response, especially over the North Atlantic, including their signs and equivalent-barotropic structures. The positive anomaly over the Urals is also qualitatively consistent with Peng et al., albeit the present response is somewhat stronger, and Peng et al.'s lacks significance. Such a positive Ural response is in strong contrast with PS85, who found no significant response. This exhibits that the present model's results extend the previous studies, in that the SSTA not only induces a barotropic response downstream of SSTA, but also remotely results in a positive height response over the Urals through a wave-train-like height anomaly chain. As displayed in Figs. 5c and d, such a wave-train chain dominates the low-frequency variability over the North Atlantic-Europe domain in both the real atmosphere and the present model. In view of the aforementioned dependence of the simulated extratropical atmospheric response to the SST anomaly on the model's intrinsic variability, it is speculated that the difference of the Ural response can be attributed to the low-frequency variability difference over the domain in the models, though the model's internal variability is not shown in Peng et al. (1995), and PS85.

When the North Atlantic response strength is compared with PS85, where a strong 500$\mathrm{hPa}$ height response with a magnitude of about $17 \mathrm{mK}^{-1}$ was obtained (the height difference between their positive/negative SSTA runs, with an SSTA maximum of $3.0 \mathrm{~K}$, is about $100 \mathrm{~m}$, so the response strength for a positive/ negative SSTA is about $50 \mathrm{~m} / 3.0 \mathrm{~K} \approx 17 \mathrm{mK}^{-1}$ ), the response here is weaker, only about $7 \mathrm{mK}^{-1}$ (17 meters of $500-\mathrm{hPa}$ height response to $2.5 \mathrm{~K}$ SSTA over the North Atlantic). The $500-\mathrm{hPa}$ height remote response over the Urals in the present study is also weak, only about $10 \mathrm{~m}$. The Ural response indicates a signal-noise ratio of around $10 / 45 \approx 22 \%$ (variance signal-noise ratio 5\%), given that the model's atmospheric internal variability (noise), represented by one standard deviation, is about $45 \mathrm{~m}$ for $500-\mathrm{hPa}$ height over the Urals (see Fig. 5b). Usually, the magnitude of the atmospheric response to a midlatitude SST anomaly is $10-20 \mathrm{mK}^{-1}$ (Robinson 2000), and the variance signal-noise ratio is $10-20 \%$ (Kushnir et al. 2002). Hence the present response strength is significantly weaker than that in most other studies. The weak response can be associated with the model's deficiency in representing lowfrequency variability. As demonstrated in the above sub-section 4.2 , low-frequency variability over the Urals is seriously underestimated. Therefore, the response in the real atmosphere may be stronger. 
a)

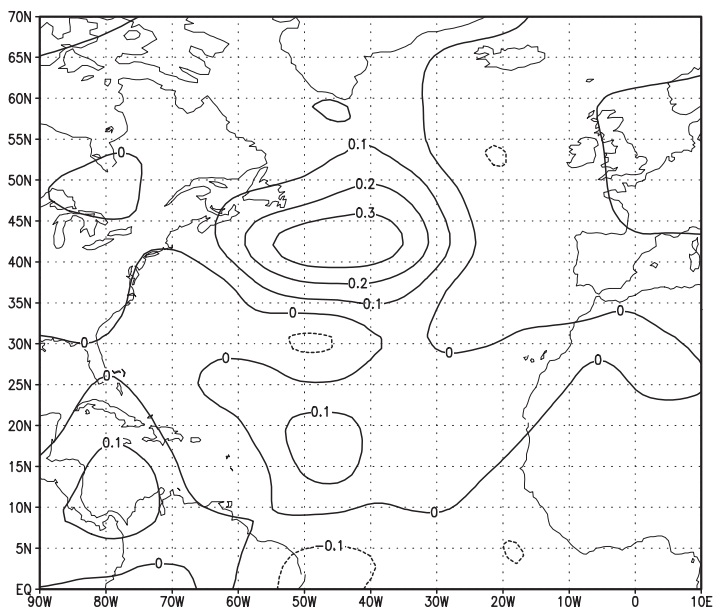

c)

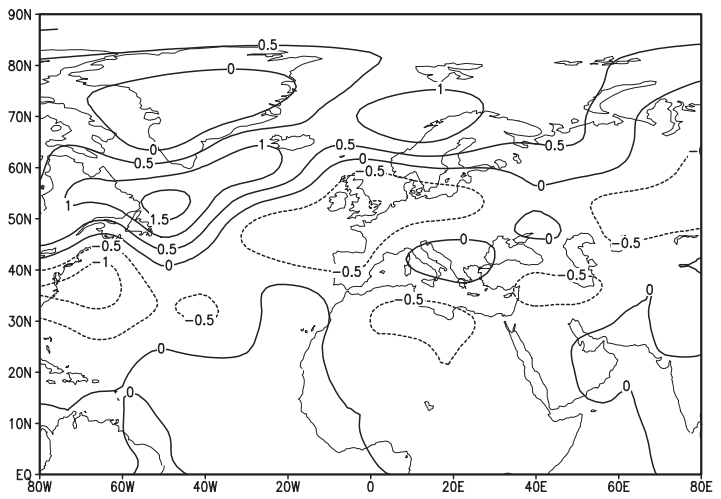

b)

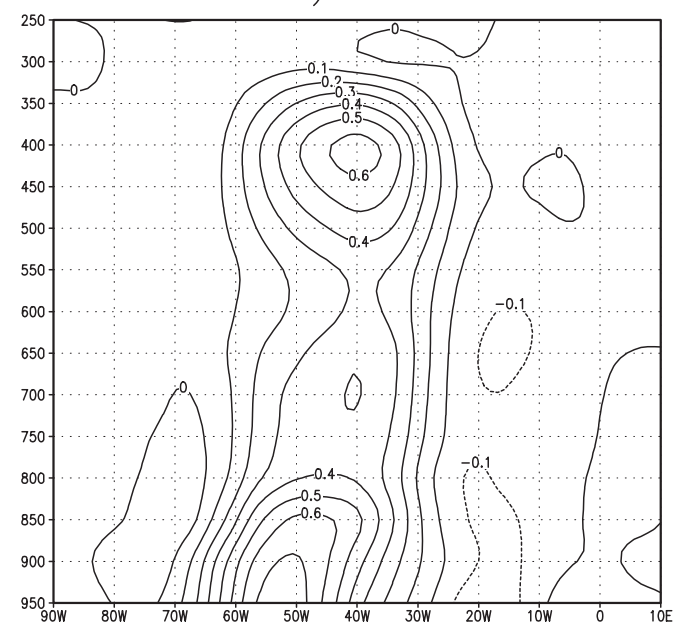

Fig. 7. (a) October-December mean anomaly of vertically-averaged heating in the SSTA runs. (b) The vertical distribution of the anomalous heating along $42.5^{\circ} \mathrm{N}$. (c) October-December vertical mean anomaly of stream function tendency due to transient vorticity flux convergence. Unit: $\mathrm{K} \mathrm{day}^{-1}$ in (a) and (b), $\mathrm{m}^{2} \mathrm{~s}^{-2}$ in (c).

\subsection{Maintenance of response}

The maintenance mechanism of the response is addressed by investigating the individual contributions of anomalous diabatic heating, and anomalous transient vorticity forcing due to transient vorticity flux convergence, the two most important among all forcings, via the LBM. Here, the transient vorticity forcing is calculated over the T42 gaussian horizontal grid and 17 vertical levels of the GCM output, then interpolated to the LBM's T21 grid at 10 equally spaced vertical levels. The diabatic heating is interpolated to the T21 grid at 19 vertical levels from the model' original T42 grid at 28 sigma levels. Figure 7 displays the two forcings. The heating anomaly over the European Continent is not so distinct as that over the North Atlantic, thus only a smaller domain is displayed. In view of the LBM is not an exact linearization version of the GCM, both the observed and the model's basic flow are used to calculate the LBM response to the forcings, despite theoretically only the GCM's basic flow should be used. The results suggest that the total LBM response under the two basic flows resembles each other, albeit the total response under the observed basic flow is slightly better than that under the model's one, when compared to the GCM response. Therefore, the LBM responses displayed below are referred to that under the observed basic flow.

The sum of the LBM geopotential height responses at $500-\mathrm{hPa}$ and $850-\mathrm{hPa}$ to the two important forcings, along with the vertical profile along $52.5^{\circ} \mathrm{N}$, are shown in Fig. 8. Comparing with Fig. 6, most of the GCM response is re- 
(a) $500 \mathrm{mb}$

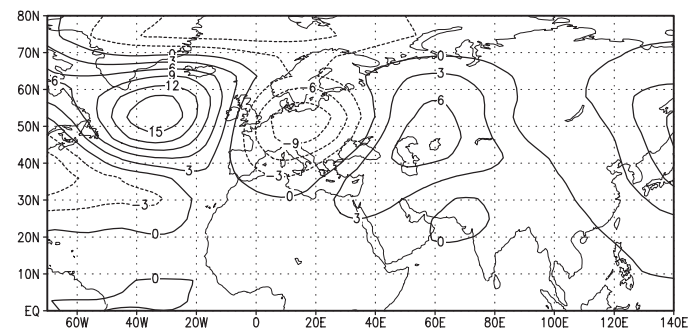

(c) along $52.5 \mathrm{~N}$

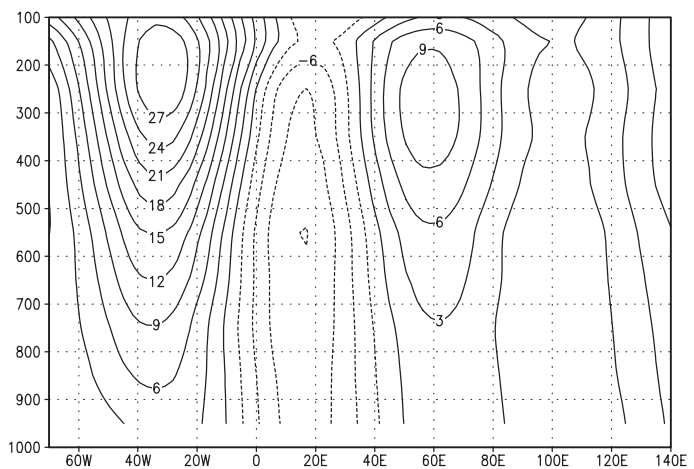

(b) $850 \mathrm{mb}$

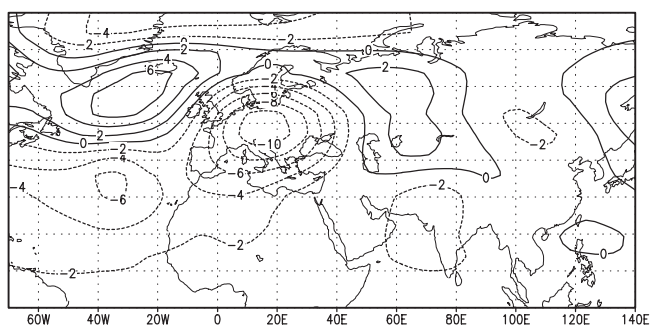

Fig. 8. Sum of the LBM response to the anomalous diabatic heating in Fig. 7a and to the anomalous stream function tendency due to anomalous transient vorticity flux convergence in Fig. 7c. (a) for $500-\mathrm{hPa}$; (b) for $850-\mathrm{hPa}$; (c) Crosssection along $52.5^{\circ} \mathrm{N}$. Unit: $\mathrm{m}$.

produced by the LBM simulated responses to the two forcings. For example, both the positive $500-\mathrm{hPa}$ height responses over the North Atlantic and over the Urals, as well as the barotropic vertical structure, are captured well, although the latter's strength is slightly weaker.

Figures 9 and 10 display the LBM's responses to the diabatic heating and the transient vorticity forcing, respectively. The response to the diabatic heating is very different from the total response. The anomalous heating induces a south-north dipole with the zero line along $50^{\circ} \mathrm{N}$ over the North Atlantic (Fig. 9a). The vertical profile of the response exhibits baroclinic structure (Fig. 9c), in strong contrast with the barotropic structure of the total response. The baroclinic response, with the maximum response slightly shifted downstream of the heating center, is in agreement with simple linear theory (e.g., Held 1983). This theory predicts a baroclinic response with a surface low downstream of extratropical heat source by solving linearized thermodynamic equation of stationary eddy. However, the heating response over the Urals, including both its strength and vertical barotropic structure, bears a strong re-

semblance to the total response. In Fig. 10, the LBM response to the transient vorticity forcing has a strongly positive height anomaly over the North Atlantic, and a negative anomaly over Europe, and both have a barotropic structure, in contrast with the preceding heating response. Because the upstream responses induced by the anomalous transient vorticity forcing are much stronger than those induced by the heating, the sum of the two responses still appears barotropic. This suggests that the anomalous transient vorticity forcing and diabatic heating jointly maintain the upstream responses, but the former plays a dominant role. Over the Urals, although the anomalous transient vorticity forcing can also induce a positive barotropic response, the response magnitude is significantly smaller than that induced by the anomalous heating. This indicates that the anomalous diabatic heating can be more important in the maintenance of the Ural response. When the GCM's basic state is applied, the main features are similar. The small differences are: 1) the total response around the Urals shifts slightly southward with maximum magnitude at $45^{\circ} \mathrm{N}$, due to one transient-induced positive height 
(a) $500 \mathrm{mb}$

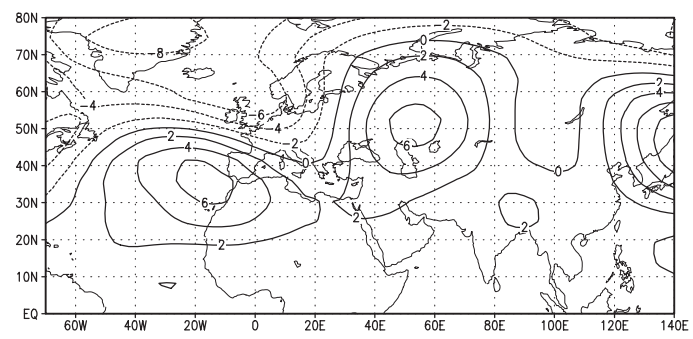

(c) along $52.5 \mathrm{~N}$

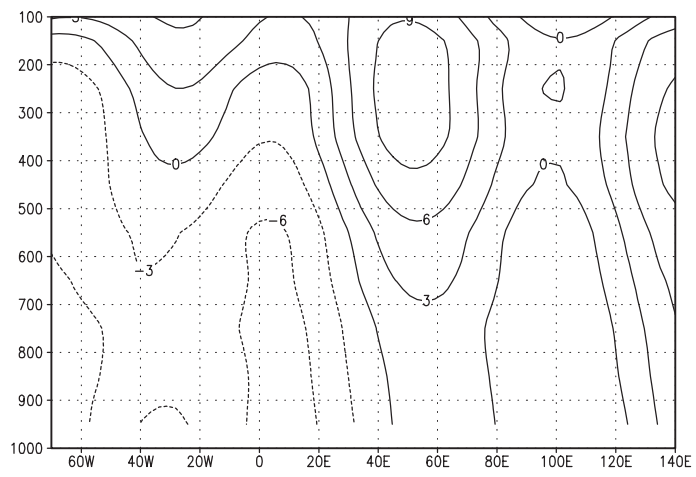

(b) $850 \mathrm{mb}$

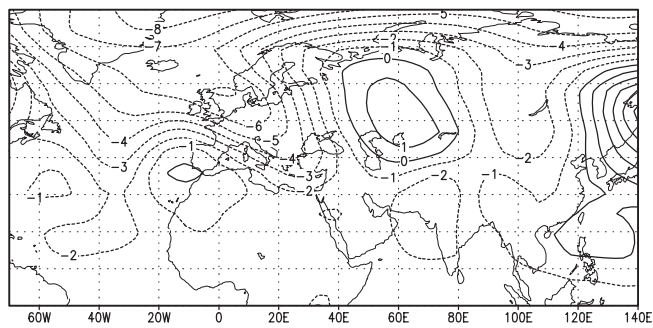

Fig. 9. Same as Fig. 8, except the response to the anomalous diabatic heating. (a) $500 \mathrm{mb}$

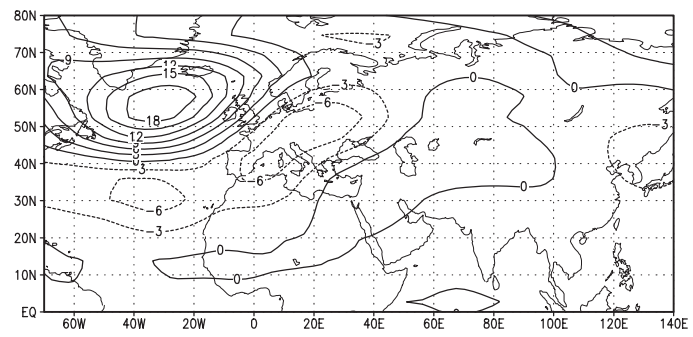

(c) along $52.5 \mathrm{~N}$

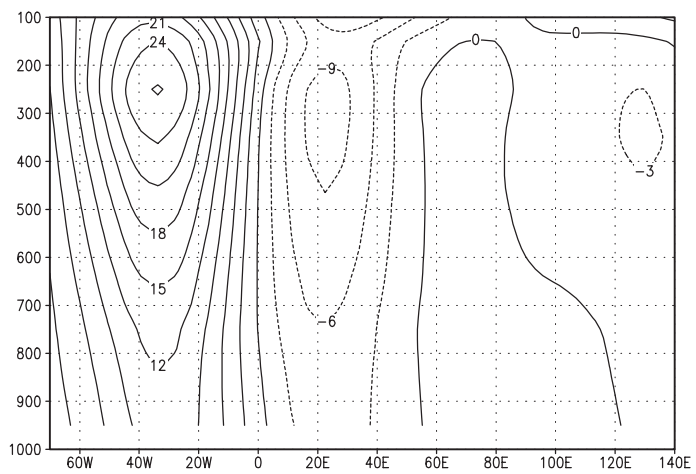

(b) $850 \mathrm{mb}$

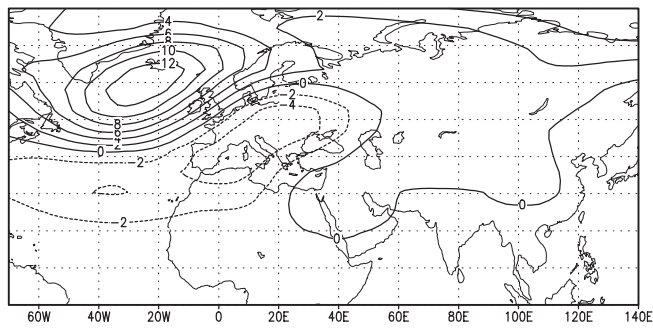

Fig. 10. Same as Fig. 8, except the response to the anomalous stream function tendency due to transient vorticity flux convergence. 
response center at the location; and, 2) the response to the heating lacks a negative pole over the North Atlantic (see Fig. 9a).

\section{Origin of response}

In the above section, one stable GCM response to the SSTA is obtained, and its maintenance is diagnosed. Due to the existence of kinds of feedback processes, one cannot deduce the initial formation mechanism of the response from its maintenance. When an SSTA is prescribed initially, it will cause anomalous heating in the overlying atmosphere by changing sensible heating flux directly. The strength of the heating anomaly is determined jointly by the SSTA (pattern and magnitude), and the atmospheric thermodynamic environment near the surface (air temperature and wind). The heating anomaly will result in atmospheric response by influencing the storm formation processes, etc. Once the atmosphere begins to adjust to the SSTA, the heating induced by the SSTA will change and differ from that at the initial stage. Latent heating processes also will involve in the process. The adjustment between heating and storm activity will never cease. A steady atmospheric response reaches only when an equilibrium state of the adjustment is formed. Therefore, the causality cannot be clarified at the equilibrium stage. In this section, the initial formation process of the steady response is explored. For a given SSTA initially, how and by what process will it impact on the atmosphere and result in a steady response? The question can be divided into the following sub-questions: What heating will be induced once the SSTA is prescribed initially? How will the heating change time-mean flow? What transient feedback will be caused? How will time-mean flow respond to the anomalous transient activity? The questions are conducted by the LBM and STM experiments.

\subsection{Prescription of initial heating}

First, one needs to estimate the heating strength and distribution induced directly by the SSTA initially. These can be deduced from the relationship of heating with the surface flux (Peng and Whitaker 1999). Generally, the heating anomaly is positively related to net surface heat flux anomalies, and surface heat fluxes are proportional to the sea-air tempera- ture contrast near the surface. Therefore, the heating anomaly is primarily proportional to the anomaly of sea-air temperature contrast. Evidently, the initial sea-air temperature contrast equals the prescribed SSTA. When the atmosphere has adjusted to the imposed SST anomaly (equilibrium stage, October-December here), the surface sea-air temperature contrast can be obtained easily from the vertical difference of air temperature near surface. Therefore one can deduce the initial SSTA-induced heating, given the anomalous sea-air temperature contrast at the equilibrium stage.

The model surface output provides air temperature at the surface and at the 2-meter height, as well as flux variables. Sea-air temperature contrast can be represented by the temperature difference between the sea surface and the 2-meter height. Figure 11 displays the difference of ensemble mean sea-air temperature contrast for October-December between the SSTA runs and the control runs. The maximum temperature contrast anomaly is only $0.7 \mathrm{~K}$, while at the initial stage this should be equal to the SSTA, with a maximum value of about $2.5 \mathrm{~K}$ (Fig. 4). It indicates that the seaair temperature contrast anomaly at the equilibrium is much weaker, only around 30 per-

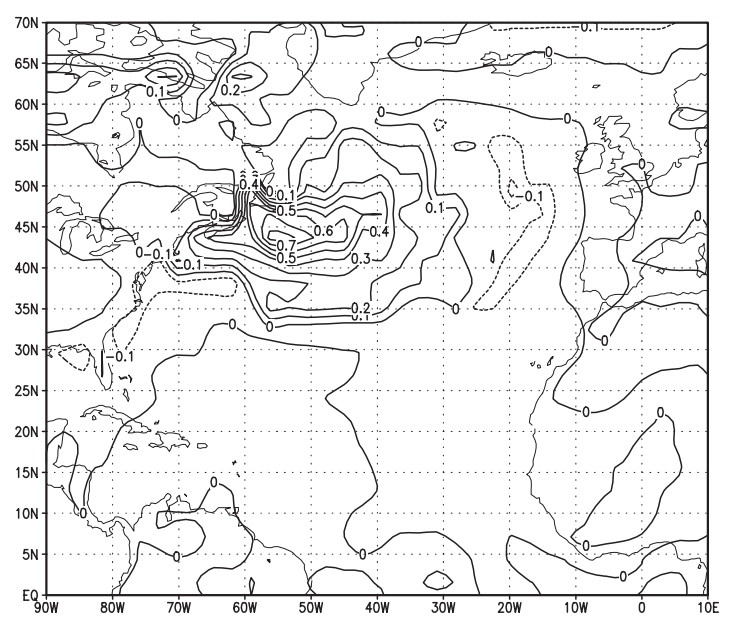

Fig. 11. October-December mean ensemble anomaly of sea-air temperature contrast at the surface in the SSTA runs. Unit: K. The sea-air temperature contrast is represented by the difference at the surface and at 2-meter height. See text. 
cent of that at the initial stage. Therefore, the column mean heating anomaly strength at the initial stage should be roughly 3 times as strong as that at equilibrium (Fig. 7a). From Fig. 7, the anomalous column-mean maximum heating is primarily situated over the SSTA and is deep, with two vertical maxima near the surface and near $400-\mathrm{hPa}$, respectively. At the initial stage, the heating should not be so deep due to the lack of transient feedback. Conversely, it should concentrate around the surface due to the strong sea-air temperature contrast there, and its vertical distribution should decay monotonically upward. This upward decrease can be mimicked with an idealized profile, $\sigma^{n}$, where $\sigma=p / p_{0}\left(p_{0}=1000-\mathrm{hPa}\right)$, and $n$ determines the decay rate. Larger $n$ defines a shallower heating and vice versa. For extratropical SSTA-induced initial heating, it should be shallower, so $n=8$ is appropriate (Peng and Whitaker 1999). Based on the anomalous air-sea temperature contrast (Fig. 11 ), and the anomalous column heating distribution at the equilibrium stage (Fig. 7a), we prescribe an idealized initial heating as in Fig. 12.

\subsection{Response to idealized heating and transient feedback}

Figure 13a displays the LBM direct response to the idealized heating. It resembles the re- sponse to the heating at equilibrium stage (Fig 9a) except for a slight northward shift of the two positive centers around the North Atlantic and the Urals. The vertical structure of the idealized-heating induced response is baroclinic over the North Atlantic but barotropic over the Urals (not shown), also similar to the response at the equilibrium (Fig. 9c). This indicates that the atmospheric responses are not very sensitive to the vertical profile of the midlatitude heating. One natural question arises: is the response sensitive to the location of the heating? Several additional experiments have been conducted, with the location of heating shifted within the North Atlantic basin, and the results exhibit that the LBM response strongly depends on where the idealized heating is specified, and only the heating prescribed as in Fig. 12a can induce such a response.

Because of the role of the basic flow in organizing transient eddies (Branstator 1995), the heating-induced anomalous flow will modulate the organization of transient eddies, and thus change the storm track. The anomalous transient eddy activity is simulated via the STM by comparing the eddy activity statistics with the observed flow, and with the heatinginduced flow added to the observed flow. Figure $13 \mathrm{~b}$ displays the difference of the transient stream function tendency due to transient vorticity flux convergence under the two basic a)

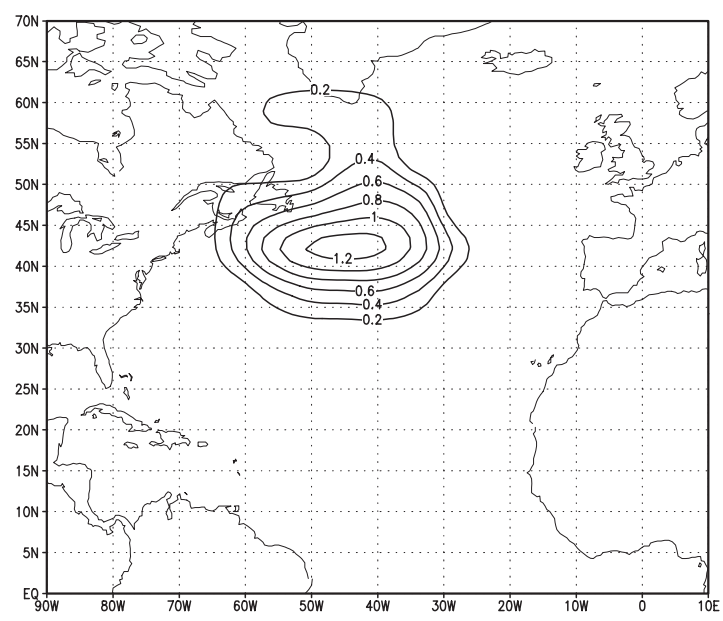

b)

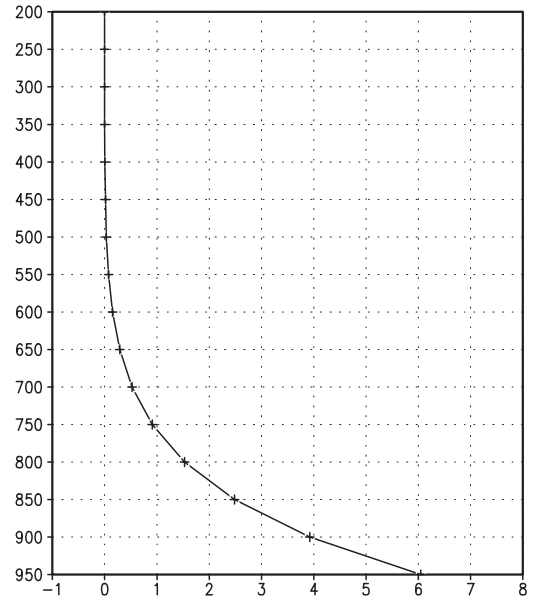

Fig. 12. Idealized heating distribution representing the SSTA-induced heating at the initial stage. In (a) is the depth-averaged heating rates, and in (b) the vertical heating profile over the maximum heating center. Unit: $\mathrm{K}$ day $^{-1}$. 
a)

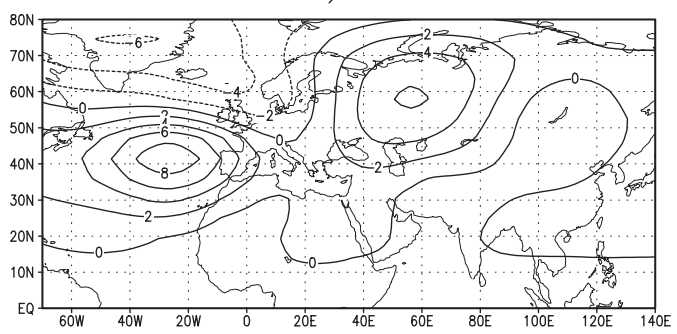

c)

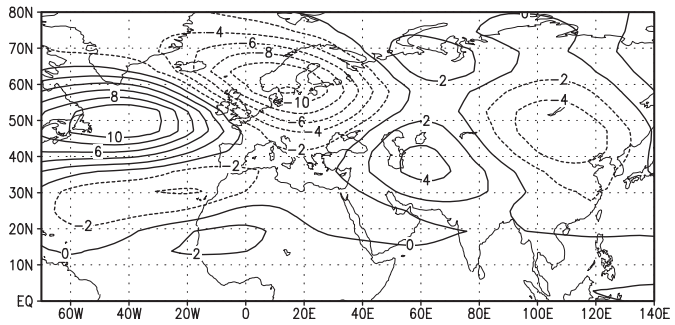

b)

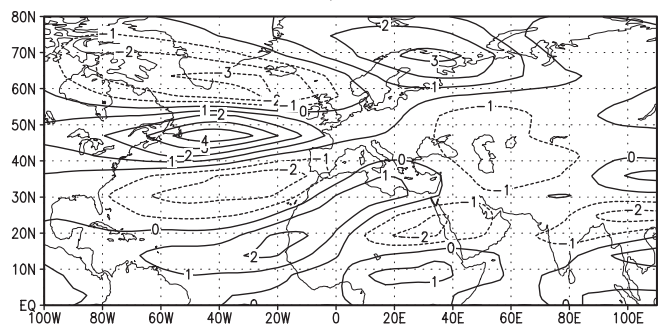

d)

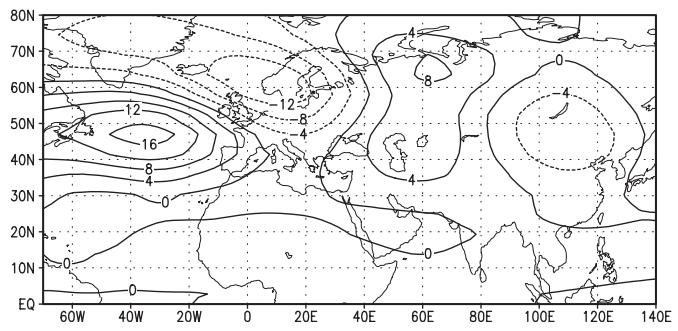

Fig. 13. (a) LBM 500-hPa height response to the idealized heating in Fig. 12. Unit: m. (b) 250-hPa anomalous stream function tendency due to the transient eddy feedback to the heating-induced anomalous flow in (a) via the linear storm track model. Unit: $\mathrm{m}^{2} \mathrm{~s}^{-2}$. (c) LBM 500-hPa response to the anomalous stream function tendency as in (b). Unit: m. (d) Sum of (a) plus (c). Unit: m.

flows, which represents the transient response to the anomalous flow (Fig. 13a) induced by the heating. From Fig. 13b, the main transient anomaly is over the position of the North Atlantic climatological storm track.

The above anomalous eddy activity will feed back on the time-mean flow, thus also resulting in a change of the mean flow. The change is not induced directly by the heating, so it is referred to as the indirect impact of the heating. The indirect impact can be estimated by the LBM response to the anomalous transient forcing. Figure 13c displays the LBM-simulated indirect impact of the idealized heating. A wavetrain-like anomaly chain with a positive anomaly over the Urals can be identified, but evidently, the strongest anomalies are over the upstream from the North Atlantic to Europe. To some extent, the response resembles the time-mean flow response to the anomalous transience at the equilibrium stage (Fig. 10a). But the downstream response in the former is relatively stronger in comparison with the latter, which indicates an un-negligible role of the transient feedback in the formation of the downstream response.
This indirect influence will interact and overlap with the anomalous flow induced by the heating directly, and thus the sum of the two influences reflects the influence of the idealized heating at the early stage. From Fig. 13d, the total atmospheric response at the stage also displays a wave-train-like anomaly chain, resembling the GCM response in Fig. $6 \mathrm{a}$ and the observational composite in Fig. 1a. Comparing the idealized heating-induced direct response (Fig. 13a) with the indirect response (Fig. 13c), one can see that the latter component is the main contributor to the two anomalies upstream, while the former component is more important for the Urals. With further feedback between time-mean flow and transient eddy activity, the heating affect will be expected to decrease gradually, in view of that the heating at the equilibrium (Fig. 7a) is much weaker than at the initial stage (Fig. 12a). Correspondingly, the anomalous transient forcing will increase, which can be seen from the greater magnitude of transient-forced response at the equilibrium (Fig. 10a), than that at the initial stage (Fig. 13c). In the end, an equilibrium state will be reached. Anomalous tran- 
sient forcing dominates the maintenance of the anomalies upstream, where exists a strong transient feedback. For the Urals, due to the relatively weak transient feedback, the heating still plays a more important role.

\section{Summary and discussions}

The circulation anomaly over the Ural Mountains is closely related to the anomalous weather and climate in East Asia. In this paper, the background circulation associated with the Ural anomaly during early winter is investigated, and one wave-train-like height anomaly chain across the Atlantic and Europe linked to the Urals is obtained. There is a strongly positive anomaly over the northwest Atlantic, and a negative anomaly over coastal Europe, when there is a positive anomaly in $500-\mathrm{hPa}$ geopotential height over the Urals. The association of the Ural anomaly with North Atlantic SST is investigated. The results demonstrate that there is a significantly positive SSTA over the northwest Atlantic, when the Urals have a positive height anomaly. To explore whether the SSTA forces the Ural anomaly, two sets of large (100 members) ensemble GCM experiments were conducted with the seasonally varying climatological SST and with the SSTA added to it. The results demonstrate that the SSTA can force a wave-train-like height response chain with a positive anomaly over the Urals, which resembles the observational background circulation associated with the Ural positive height anomaly. This suggests that the previously demonstrated influence of the SSTA on the atmospheric circulation (e.g., PS85) extends from the North Atlantic to the Ural Mountains through the wave-train-like anomaly chain across coastal Europe. This is the primary conclusion of this study.

To further understand the maintenance mechanism of the response, the individual roles of diabatic heating and transient flux convergence, the two most important forcings, are diagnosed via a linear baroclinic model. It is found that the roles of the two forcings are not the same important for the individual anomalies that compose the wave-train-like response chain. The two anomalies upstream over the North Atlantic, and over coastal Europe are jointly maintained by the two forcings, while anomalous transient forcing plays a dominant role. For the Ural response, the anomalous diabatic heating plays a critical role, although the anomalous transient forcing also modulates the response.

In order to explore the initial formation processes of the responses, an idealized heating representing the initial SSTA-induced anomalous heating is prescribed as a forcing of the LBM. The results suggest that such an idealized heating will induce a response with a south-north dipole anomaly over the North Atlantic, and a positive anomaly over the Urals, which is similar to the response to the anomalous diabatic heating at the equilibrium stage. Due to the modulation of the time-mean flow in organizing transient eddies, the heatinginduced anomalous flow will modulate the organization of transient eddies and thus change the storm track. An STM is employed to mimic the transient feedback to the heating-induced anomalous flow by comparing the eddy activity statistics under the observed flow, and with the heating-induced flow added to the observed flow, and the results indicate that the heating will result in a strong storm activity anomaly over the North Atlantic, but only have a weak influence over the Urals. When the LBM is integrated to address time-mean flow response to the induced anomalous transient forcing, a wave-train-like response with a positive but weak height anomaly over the Urals is obtained. The initial process of the response to the SST anomaly can be summarized as follows. First, the SSTA will induce a strong but shallow heating. The heating will induce a baroclinic south-north dipole response over the Atlantic and a barotropic positive height anomaly over the Urals. The heating-induced response will cause a strong transient feedback over the Atlantic and a relatively weak transient feedback dowenstream. The anomalous transient feedback will induce a wave-train-like anomaly chain across the North Atlantic and Europe to the Urals. With the not-ceasing feedback between eddy activity and time-mean flow as well as the heating, the heating impact is expected to decrease gradually, while the anomalous transient forcing affect is expected to increase. In the end, an equilibrium state will be reached. Anomalous transient forcing will dominate the maintenance of the anomalies from the North Atlantic to Europe, where exists 


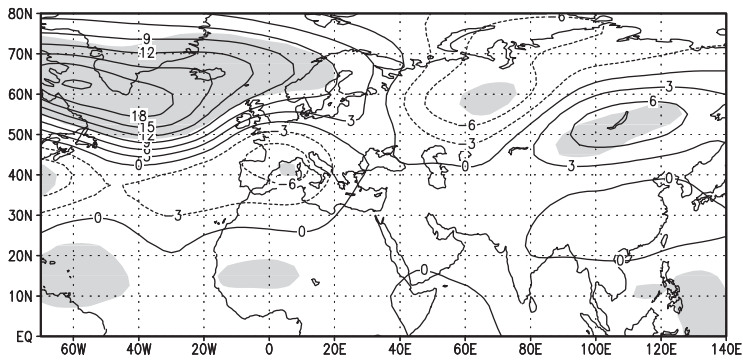

Fig. 14. Same as in Fig. 6a, but for February-April.

a strong transient eddy feedback. For the Urals, due to the relatively weak transient feedback, the heating still plays a more important role, although it is modulated by transient forcing. The maintenance of the GCM response in October to December is in agreement with this process.

Whether there exists a similar response in late winter is an intriguing question. Figure 14 displays the mean response to the SSTA from February to April. Clearly, it is very different from early winter, in that it is a phase-reversed NAO-like dipole. The late winter response, with its sign reversed, is similar to the atmospheric response to the North Atlantic SST tri-pole (Fig. 2 in Peng et al. 2002 and Fig. 1a in Sutton et al. 2001) in a number of recent studies (e.g., Czaja and Marshall 2001; Peng et al. 2002; Rodwell et al. 1999; Sutton et al. 2001). This may be explained because the SSTA, when with the sign reversed, is similar to the northern component of the SST tri-pole. The significant difference of the response in early winter and in late winter can be attributed to the difference in the background circulation and the dominant low-frequency pattern during the two seasons (Peng and Robinson 2001; Hall et al. 2001).

As mentioned in the text, the GCM response in the present study is significantly weak in comparison with the previous studies, and this may be attributed to the model's weak representation of low frequency variability. Further research into the SSTA impact on the Urals, therefore, is necessary using models that better represent the atmospheric variability, lowfrequency pattern and storm track.

\section{Acknowledgements}

The author is grateful to the two anonymous reviewers for their helpful suggestions and constructive critiques, and highly appreciates Dr. Jeffery Yin's help on the writing of the manuscript. He also wishes to thank Drs. Shiling Peng and Walter Robinson for helpful discussions, Dr. Jeffrey Whitaker for providing the linear models, and Dr. Jialin Lin for reading through the manuscript. This research is supported in part by a grant from the NOAA's CLIVAR Atlantic program.

\section{References}

Branstator, G., 1995: Organization of storm track anomalies by recurring low-frequency circulation anomalies. J. Atmos. Sci., 52, 207-226.

Czaja, A. and C. Frankignoul, 2002: Observed impact of Atlantic SST anomalies on the North Atlantic Oscillation. J. Climate, 15(6), 606-623.

Dole, R.M. and N.D. Gordon, 1983: Persistent anomalies of the extratropical northern hemisphere wintertime circulation: geographical distribution and regional persistence characteristics. Mon. Wea. Rev., 111, 1567-1586.

Drevillon, M., L. Terray, P. Rogel, and C. Cassou, 2001: Mid latitude Atlantic SST influence on European winter climate variability in the NCEP reanalysis. Clim. Dyn., 18, 331-344.

Hall, N.M.J., J. Derome, and H. Lin, 2001: The extratropical signal generated by a mid latitude SST anomaly. Part I: Sensitivity at equilibrium, J. Climate, 14, 2035-2053.

Held, I.M., 1983: Large-scale dynamical processes in the atmosphere, stationary and quasistationary eddies in the extratropical troposphere: theory, Academic Press, Editor (B. Hoskins and R. Pearce Ed.), 127-168.

Kalney, E., 1996: The NCEP/NCAR 40-year reanalysis project. Bull. Amer. Meteor. Soc., 77, 437-471.

Kushnir, Y. and I.M. Held, 1996: Equilibrium atmospheric response to North Atlantic SST anomalies. J. Climate, 9, 1208-1220.

Kushnir, Y., W.A. Robinson, I. Blade, N.M.J. Hall, S. Peng, and R. Sutton, 2002: Atmospheric GCM response to extratropical SST anomalies: Synthesis and evaluation. J. Climate, 15(16), 2233-2256.

Li, S. and L. Ji, 2001: Background circulation characteristics of the persistent anomalies of the summertime circulation over the Ural Mountains. Acta Meteorologica Sinica, 59(3), 280293 (in Chinese). 
Namias, J., 1964: Seasonal persistence and recurrence of European blocking during 1958-1960. Tellus, 16, 394-407.

, 1973: Thermal communication between the sea surface and the lower troposphere, J. Phys. Oceanogr., 3, 373-378.

Palmer, T.N. and Z. Sun, 1985: A modeling and Observational study of the relationship between sea surface temperature in the North-west Atlantic and the atmospheric general circulation. Quart. J. Roy. Meteor. Soc., 111, 947-975.

Peng, S., L.A. Mysak, H. Ritchie, J. Derome, and B. Dugas, 1995: The differences between early and midwinter atmospheric responses to sea surface temperature anomalies in the northwest Atlantic. J. Climate, 8, 137-157.

and J.S. Whitaker, 1999: Mechanism determining the atmospheric response to midlatitude SST anomalies. J. Climate, 12, 13931408.

and W.A. Robinson, 2001: Relationships between atmospheric internal variability and the responses to an extratropical SST anomaly. $J$. Climate, 14, 2943-2959.

- — , and S. Li, 2002: North Atlantic SST forcing of the NAO and relationships with intrinsic hemispheric variability. Geophy. Res. Lett., 29(8), 117-1:4.

$\longrightarrow,-$, and 2003: Mechanisms for the NAO responses to the North Atlantic SST tripole, J. Climate, 16(12), 1987-2004.

Robinson, W.A., 2000: Review of WETS-The workshop on extratropical SST anomalies. Bull. Amer. Meteor. Soc., 81, 567-577.

Rayner, N.A., E.B. Horton, D.E. Parker, C.K. Folland, and R.B. Hackett, Version 2.2 of the global sea surface temperature data set, 19031994, Climate Research Technical Note 74, Hadley Center for Climate Prediction and Research, UK Meteorological Office, 1996.

Rodwell, M.J., D.P. Rodwell, and C.K. Folland, 1999: Oceanic forcing of the wintertime North Atlantic Oscillation and European climate, Nature, 398, 320-323.

Sutton, R.T., W.A. Norton, and S.P. Jewson, 2001: The North Atlantic Oscillation-what role for the ocean?. Atmos. Sci. Lett., 1, 89-100.

Ting, M. and S. Peng, 1995: Dynamics of the early and middle winter atmospheric responses to the Northwest Atlantic SST anomalies. J. Climate, 8, 2239-2254.

Whitaker, J.S. and P.D. Sardeshmukh, 1998: A linear theory of extratropical synoptic statistics. J. Atmos. Sci., 44, 237-258.

Ye, D.-Z., S.-Y. Tao, et al., 1962: The study on wintertime blocking pattern of the northern hemisphere. Beijing: Chinese Science Press, 220pp. (in Chinese) 